\title{
Effects of physical exercise on cognitively impaired older adults: a systematic review
}

\author{
Lenka Sontáková ${ }^{1}$, Alžběta Bártová2, Klára Dad'ová1,*, Iva Holmerová2, \\ Michal Šteffl ${ }^{1}$
}

1 Faculty of Physical Education and Sport, Charles University, Prague, Czech Republic

2 Faculty of Humanities, Charles University, Prague, Czech Republic

* Corresponding author: dadova@ftvs.cuni.cz

\begin{abstract}
Background. The main aim of this study was to estimate the effect of physical activities (PA) on cognitive functions (CF) in cognitively impaired older adults divided according to the impairment severity.

Methods. We searched Web of Science, Scopus, and PubMed for randomized controlled trials (RCT). We focused on the effect of exercise on CF in intervention groups and control groups separately in people with cognitive impairment across three levels - borderline intact, mild, and moderate cognitive impairment separately.

Results. Data from 40 studies involving 1,780 participants from intervention groups and 1,508 participants from control groups were analyzed. $37.0 \%$ of intervention groups presented a statistically significant beneficial effect of PA on CF, while 5\% presented a statistically significant harmful effect of PA on CF. $40.0 \%$ of the control groups showed a significant decrease in CF. 54.3\% interventions had a statistically significant beneficial effect (Hedges' $g>0$ ). However, there was a great variability between the studies in terms of exercise program description and cognitive impairment of the subjects.

Conclusions. Physical exercise was associated with cognitive function improvement in older people with cognitive impairment. The positive effect is stronger in people with a mild level of cognitive impairment.
\end{abstract}

\section{KEYWORDS}

physical activity; dementia; ageing; aerobic exercise; resistance exercise; cognitive function

DOI

$10.14712 / 23366052.2021 .5$

(c) 2021 The Authors. This is an open-access article distributed under the terms of the Creative Commons Attribution License (http://creativecommons.org/licenses/by/4.0), which permits unrestricted use, distribution, and reproduction in any medium, provided the original author and source are credited. 


\section{BACKGROUND}

The number of older adults with dementia is on the rise due to ageing of the global population. Current estimates suggest that more than 131.5 million people will be affected by dementia by the year 2050 (Sha et al., 2016). Dementia is generally characterized by a progressive decline in cognitive and physical function, often leading to a loss of independence, and institutionalization in some cases (Winblad et al., 2016). Thus, dementia impacts not only the daily lives of individuals diagnosed with the condition but also their families and broader society. During the past two decades, epidemiological research has highlighted the link between modifiable lifestyle factors and cognitive functions. For example, current evidence has demonstrated that a physically active lifestyle may help to delay the onset of cognitive decline and to slow down disease progression (Rolland et al., 2008). Also, physically active individuals have been shown to have a smaller risk of developing dementia or mild cognitive impairment than those who do not take part in any regular physical activity (Rockwood \& Middleton, 2007). Moreover, results from several prospective studies have shown that exercise and physical fitness seem to have a positive effect on brain health (Blondell et al., 2014; Stephen et al., 2017). In particular, it has been demonstrated that regular physical activity in mid-life is associated with a lower risk of dementia in later life (Chen et al., 2016), as well as that one of the most effective protections against neurodegenerative or vascular dementia is to be sufficiently physically active from mid-life (Rolland et al., 2008). In addition, it is now well known that exercise interventions increase the functional performance and activities of daily living in patients with cognitive impairment (Garuffi et al., 2013; Hauer et al., 2012; Pitkala et al., 2013; Schwenk et al., 2014; Steinberg et al., 2009). Partial confirmation of a general positive effect of physical exercise was seen as well as stratified effect according to the type of exercise undertaken on executive function, memory (Gates et al., 2013), and global cognition (Groot et al., 2016; Song et al., 2018; Wang et al., 2014) in individuals with mild cognitive impairment. However, there are other important variables that may influence results; for example the effects of exercise on cognitive function in people in relation to the level of cognitive impairment, frequency of sessions or duration of interventions. It is necessary to focus attention on these variables to better understand this complex issue.

Therefore, the main aim of this study was to investigate which type of exercise interventions work effectively in the prevention of cognitive decline in older adults stratified according to the level of cognitive impairment. Additionally, we aimed to investigate the association between other factors, e.g. whether there is a difference between passive and active controls. We hypothesized that there is a difference between exercise programs (mainly from the duration point of view) and that the effect might vary across different levels of cognitive impairment. We also hypothesized that different activity programs in control groups might influence the results. For example, a social program without physical activities may be beneficial for older adults with cognitive impairment. We also assumed that social or education activities in control groups might be more helpful against the cognitive decline rather than inactivity in passive control groups. 


\section{METHODS}

This review assessed the effects of physical exercise programs on people with cognitive impairment. It is reported in accordance with the Preferred Reporting Items for Systematic Reviews and Meta-Analyses (PRISMA) statement (Moher et al., 2019). A compiled PRISMA checklist is included in Table 1.

Table 1 Checklist of items to include when reporting a systematic review or meta-analysis

\begin{tabular}{ccc}
\hline Section/topic & Checklist item & $\begin{array}{l}\text { Reported } \\
\text { on page \# }\end{array}$ \\
\hline
\end{tabular}

\section{TITLE}

Title

1 Identify the report as a systematic review, meta-analysis, or both.

51

ABSTRACT

Structured summary

2 Provide a structured summary including, as applicable: background;

51

objectives; data sources; study eligibility criteria, participants, and interventions; study appraisal and synthesis methods; results; limitations; conclusions and implications of key findings; systematic review registration number.

\section{INTRODUCTION}

Rationale

3 Describe the rationale for the review in the context of what is already known.

Objectives

4 Provide an explicit statement of questions being addressed with reference to participants, interventions, comparisons, outcomes, and study design (PICOS).

\section{METHODS}

Protocol and registration

5 Indicate if a review protocol exists, if and where it can be accessed (e.g., Web address), and, if available, provide registration information including registration number.

Eligibility criteria

6 Specify study characteristics (e.g., PICOS, length of follow-up) and report characteristics (e.g., years considered, language, publication status) used as criteria for eligibility, giving rationale.

Information sources

7 Describe all information sources (e.g., databases with dates of coverage, contact with study authors to identify additional studies) in the search and date last searched.

Search

8 Present full electronic search strategy for at least one database, including

Table 2 any limits used, such that it could be repeated.

Study selection

9 State the process for selecting studies (i.e., screening, eligibility, included in systematic review, and, if applicable, included in the meta-analysis).

Data collection process

10 Describe method of data extraction from reports (e.g., piloted forms, independently, in duplicate) and any processes for obtaining and confirming data from investigators.

Data items

11 List and define all variables for which data were sought (e.g., PICOS, funding sources) and any assumptions and simplifications made. 


\begin{tabular}{|c|c|c|c|}
\hline Section/topic & $\#$ & Checklist item & $\begin{array}{l}\text { Reported } \\
\text { on page \# }\end{array}$ \\
\hline $\begin{array}{l}\text { Risk of bias in individual } \\
\text { studies }\end{array}$ & 12 & $\begin{array}{l}\text { Describe methods used for assessing risk of bias of individual studies } \\
\text { (including specification of whether this was done at the study or outcome } \\
\text { level), and how this information is to be used in any data synthesis. }\end{array}$ & $\begin{array}{c}59 \\
\text { Table } 4\end{array}$ \\
\hline Summary measures & 13 & State the principal summary measures (e.g., risk ratio, difference in means). & $57-58$ \\
\hline Synthesis of results & 14 & $\begin{array}{l}\text { Describe the methods of handling data and combining results of studies, } \\
\left.\text { if done, including measures of consistency (e.g., }{ }^{2}\right) \text { for each meta-analysis. }\end{array}$ & $57-58$ \\
\hline $\begin{array}{l}\text { Risk of bias across } \\
\text { studies }\end{array}$ & 15 & $\begin{array}{l}\text { Specify any assessment of risk of bias that may affect the cumulative } \\
\text { evidence (e.g., publication bias, selective reporting within studies). }\end{array}$ & - \\
\hline Additional analyses & 16 & $\begin{array}{l}\text { Describe methods of additional analyses (e.g., sensitivity or subgroup } \\
\text { analyses, meta-regression), if done, indicating which were pre-specified. }\end{array}$ & - \\
\hline \multicolumn{4}{|c|}{ RESULTS } \\
\hline Study selection & 17 & $\begin{array}{l}\text { Give numbers of studies screened, assessed for eligibility, and included in } \\
\text { the review, with reasons for exclusions at each stage, ideally with a flow } \\
\text { diagram. }\end{array}$ & $\begin{array}{l}57-60, \\
\text { Figure } 1\end{array}$ \\
\hline Study characteristics & 18 & $\begin{array}{l}\text { For each study, present characteristics for which data were extracted } \\
\text { (e.g., study size, PICOS, follow-up period) and provide the citations. }\end{array}$ & $\begin{array}{l}\text { Tables } \\
3,4,5\end{array}$ \\
\hline $\begin{array}{l}\text { Risk of bias within } \\
\text { studies }\end{array}$ & 19 & $\begin{array}{l}\text { Present data on risk of bias of each study and, if available, any outcome } \\
\text { level assessment (see item 12). }\end{array}$ & - \\
\hline $\begin{array}{l}\text { Results of individual } \\
\text { studies }\end{array}$ & 20 & $\begin{array}{l}\text { For all outcomes considered (benefits or harms), present, for each study: } \\
\text { (a) simple summary data for each intervention group (b) effect estimates } \\
\text { and confidence intervals, ideally with a forest plot. }\end{array}$ & $\begin{array}{l}\text { Tables } \\
6,7,8\end{array}$ \\
\hline Synthesis of results & 21 & $\begin{array}{l}\text { Present results of each meta-analysis done, including confidence intervals } \\
\text { and measures of consistency. }\end{array}$ & - \\
\hline $\begin{array}{l}\text { Risk of bias across } \\
\text { studies }\end{array}$ & 22 & $\begin{array}{l}\text { Present results of any assessment of risk of bias across studies } \\
\text { (see Item 15). }\end{array}$ & - \\
\hline Additional analysis & 23 & $\begin{array}{l}\text { Give results of additional analyses, if done (e.g., sensitivity or subgroup } \\
\text { analyses, meta-regression [see Item 16]). }\end{array}$ & - \\
\hline \multicolumn{4}{|c|}{ DISCUSSION } \\
\hline Summary of evidence & 24 & $\begin{array}{l}\text { Summarize the main findings including the strength of evidence for each } \\
\text { main outcome; consider their relevance to key groups (e.g., healthcare } \\
\text { providers, users, and policy makers). }\end{array}$ & $70-71$ \\
\hline Limitations & 25 & $\begin{array}{l}\text { Discuss limitations at study and outcome level (e.g., risk of bias), and at } \\
\text { review-level (e.g., incomplete retrieval of identified research, reporting } \\
\text { bias). }\end{array}$ & 71 \\
\hline Conclusions & 26 & $\begin{array}{l}\text { Provide a general interpretation of the results in the context of other } \\
\text { evidence, and implications for future research. }\end{array}$ & 71 \\
\hline \multicolumn{4}{|c|}{ FUNDING } \\
\hline Funding & 27 & $\begin{array}{l}\text { Describe sources of funding for the systematic review and other support } \\
\text { (e.g., supply of data); role of funders for the systematic review. }\end{array}$ & 72 \\
\hline
\end{tabular}


The PICO (population, intervention, comparisons, and outcomes) framework was used for framing the inclusion criteria (see below) (Higgins et al., 2019).

- Participants: people $>50$ years of age with a cognitive impairment

- Intervention: physical exercise interventions

- Comparisons: active or passive controls with no additional physical activities

- Outcomes: cognitive function

\section{Inclusion criteria for this study}

Based on the above-mentioned PICO framework, the following inclusion criteria were applied:

- only data from randomized controlled trials (RCT)

- the participants had to be diagnosed with any stage of cognitive impairment by one of the standardized tools

- written in the English language

\section{Exercise intervention}

We considered only exercise programs that require increased energy output such as aerobic, resistance exercise, walking, dancing, various types of combat activities or sports games. The intervention programs involving a combination of physical exercise and cognitive training were not included. In addition to the program itself, we focused on the duration of exercise program and exercise frequency. Regarding exercise program duration and frequency of exercise per week, we used the same classification as Forbes et al (2015) in the Cochrane systematic review - "up to three times per week" or "more than three times per week" and "up to 12 weeks" or "more than 12 weeks" (Forbes et al., 2015).

According to activities that were prescribed, we have also divided control groups into two categories - active and passive control groups. All control groups where extra activities that could have potentially been beneficial for cognitive functions (for example, attention-control educational programs, social visits, or recreational activities such as card playing or home craftwork), were categorized as "active control groups". Control groups asked to maintain their usual activities were categorized as "passive control groups".

\section{Cognitive function}

The following global cognitive function tests were considered appropriate:

- Mini-Mental State Examination (MMSE) (Folstein et al., 1983)

- Rapid Evaluation of Cognitive Function (ERFC) (Gil et al., 1986)

- Alzheimer's Disease Assessment Scale-Cognitive Subscale (ADAS-Cog) (Mohs et al., 1997)

- Montreal Cognitive Assessment (MoCA) (Nasreddine et al., 2005)

- Cambridge Cognitive Examination (CAMCOG) (Roth et al., 1998) 


\section{Search strategy}

The analysis was conducted by identifying relevant papers referenced in the Web of Science, Scopus, and PubMed. Search terms used in all databases are presented in Table 2.

Table 2 Search results in electronic databases

\begin{tabular}{|c|c|c|}
\hline DATABASE & KEY & NUMBER \\
\hline Web of Science & $\begin{array}{l}\text { TOPIC: (training) OR TOPIC: (exercise) OR TOPIC: (physical) OR TOPIC: (activit*) AND } \\
\text { TOPIC: (“Mini-Mental State Examination”) OR TOPIC: (MMSE) OR TOPIC: (“Cambridge } \\
\text { Cognitive Examination") OR TOPIC: (CAMCOG) OR TOPIC: ("Montreal Cognitive } \\
\text { Assessment") OR TOPIC: (MOCA) OR TOPIC: ("Alzheimer's Disease Assessment Scale- } \\
\text { Cognitive Subscale") OR TOPIC: (ADAS-Cog) OR TOPIC: ("Rapid Evaluation of Cognitive } \\
\text { Functions test”) OR TOPIC: (ERFC) AND TITLE: (dementia) OR TITLE: (Alzheimer*) OR } \\
\text { TITLE: (cognitive) OR TITLE: (MCI) AND TITLE: (randomized) OR TITLE: (randomised) } \\
\text { OR TITLE: (trial) OR TITLE: (intervention) }\end{array}$ & 425 \\
\hline Scopus & $\begin{array}{l}\text { ( ( TITLE ( training ) OR TITLE ( exercise ) OR TITLE ( physical ) OR TITLE ( activit*) ) ) } \\
\text { AND ( ( TITLE-ABS-KEY (“Mini-Mental State Examination”) OR TITLE-ABS-KEY } \\
\text { ( mmse ) OR TITLE-ABS-KEY (“Cambridge Cognitive Examination”) OR TITLE-ABS- } \\
\text { KEY ( camcog ) OR TITLE-ABS-KEY (“Montreal Cognitive Assessment”) OR TITLE-ABS- } \\
\text { KEY ( moca ) OR TITLE-ABS-KEY ("Alzheimer's Disease Assessment Scale-Cognitive } \\
\text { Subscale”) OR TITLE-ABS-KEY (“Rapid Evaluation of Cognitive Functions test”) OR } \\
\text { TITLE-ABS-KEY ( erfc ) ) ) AND ( ( TITLE ( dementia ) OR TITLE ( alzheimer* ) OR TITLE } \\
\text { ( cognitive ) OR TITLE ( mci ) ) ) AND ( ( TITLE-ABS-KEY ( randomized ) OR TITLE-ABS- } \\
\text { KEY ( randomised ) OR TITLE-ABS-KEY ( trial ) OR TITLE-ABS-KEY ( intervention ) )) } \\
\text { AND NOT ( ( TITLE-ABS-KEY ( review ) OR TITLE-ABS-KEY ( meta-analysis ) OR TITLE- } \\
\text { ABS-KEY ( protocol ) ) ) }\end{array}$ & 460 \\
\hline PubMed & 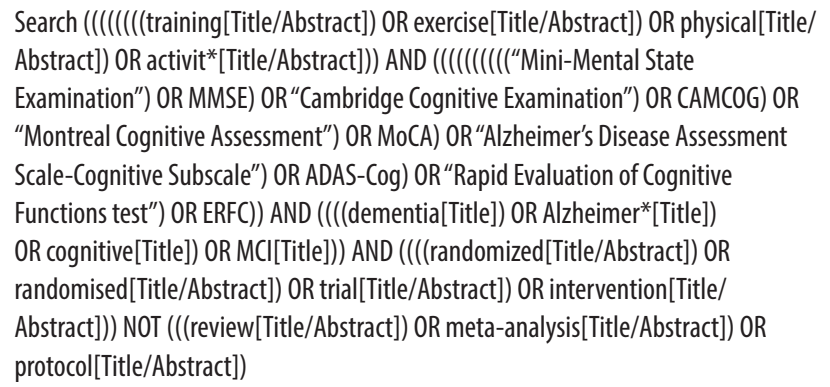 & 830 \\
\hline
\end{tabular}

\section{Data extraction and quality assessment}

All potential papers were first downloaded into EndNote. Then, our three reviewing authors (LS, AT, and MS) deleted all the duplicates and scanned the titles and abstracts of the papers in order to identify studies that had the potential to meet the eligibility criteria. Full texts were subsequently assessed for eligibility by reviewers $\mathrm{KD}$, MS and $\mathrm{IH}$ who extracted the data. Any disagreements among reviewers were resolved through discussions.

We used the Physiotherapy Evidence Database (PEDro) scale to assess the methodological quality of the included studies (Maher et al., 2003). 


\section{Data collection}

We collected the following data for both exercise groups and control groups separately: the post/pre-intervention mean of the cognitive function test with a $95 \%$ confidence interval (CI) and/or standard deviation (SD), if they were not described, we collected means of the cognitive function tests from baselines and after intervention. Additionally, we collected information about the type of exercise and control group activities, age of participants, female ratio, exercise program duration, and frequency of exercise.

\section{Cognitive impairment classification}

We divided the participants according to the level of their cognitive impairment into three categories - borderline intact, mild, and moderate cognitive impairment. In the classification, we used the mean of the baseline cognitive function test using the standard classification of each diagnostic tool from which it was calculated.

\section{Data analysis}

To see the effect of physical activity on cognitive function of participants, we calculated Hedges' $g$ (Hedges, 1981) for intervention groups and control groups separately as well as for both groups together as follows:

$$
\text { Hedges' } g=\frac{M_{I G}-M_{C G}}{S D_{\text {pooled }}} \times\left(\frac{N-3}{N-2.25}\right) \times \sqrt{\frac{N-2}{N}}
$$

where $\mathrm{M}_{\mathrm{IG}}-\mathrm{M}_{\mathrm{CG}}$ is the difference in mean changes in intervention and control groups and $\mathrm{SD}_{\text {pooled }}$ is the pooled and weighted standard deviation. Hedges' $\mathrm{g}$ is interpreted as:

- Small Effect $=0.2$

- Medium Effect $=0.5$

- Large Effect $=0.8$

Negative values represented a harmful effect (i.e. decrease of cognitive functions) of intervention. To test statistical significance we calculated 95\% Confidence Interval (CI) for each study as follows:

$$
95 \% C I=g \pm S E \times 1.96
$$

where SE is standard error calculated as:

$$
S E=\sqrt{\frac{n_{1}+n_{2}}{n_{1} \times n_{2}}+\frac{g^{2}}{2\left(n_{1}+n_{2}\right)}}
$$

If the post-pre intervention mean and SD were not available in the paper, we calculated the post-pre intervention mean as the post-intervention mean minus the pre-intervention mean and SD was estimated as: 


$$
S D_{\text {dif }}=\sqrt{S D_{\text {pre }}^{2}+S D_{\text {post }}^{2}-\left(2 \times \operatorname{Corr} \times S D_{\text {pre }} \times S D_{\text {post }}\right)}
$$

We used Corr $=0.8$ based on the assumption of a relatively high correlation between pre and post-measurements.

The statistics were calculated using Microsoft Excel.

\section{RESULTS}

We included 40 RCT in the final analysis out of the 1,258 publications resulting from the database search. These were controlled trials on physical activity and its effect on cognitive functions in people with cognitive impairment. Figure 1 shows the PRISMA flow diagram.

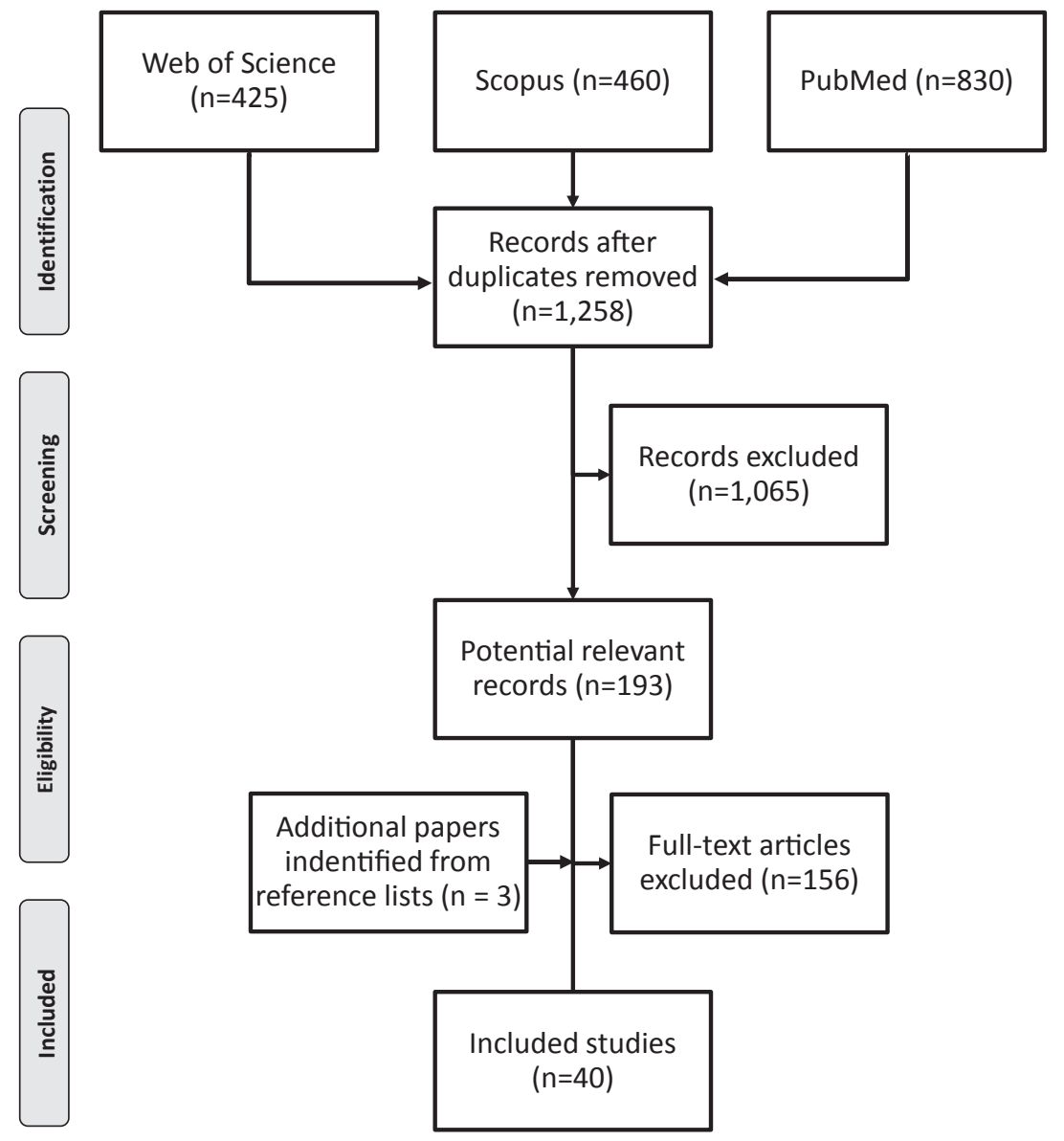

Figure 1 Flowchart illustrating the different phases of the search and study selection 
Across the studies, we extracted data from 3,288 participants, the average age was 77.1 years and the average female ratio was $69.1 \%$. The shortest duration of the exercise program was 6 weeks, and the longest was 60 weeks. As the main outcome, the following were used: 31× MMSE (Folstein et al., 1983), 5× MoCA (Nasreddine et al., 2005), 1× ERFC (Gil et al., 1986), and 3× ADAS-Cog (Mohs et al., 1997). The majority of participants lived in their own homes (21 studies). 19 studies came from Europe, 14 from Asia, 4 from South America, 2 from North America and 1 from Australia. The basic data on studies included in the analyses are presented in Table 3. All of the included studies were considered to have a good methodological quality, scoring between 7 and 9 points according to the PEDro. The methodological quality of the included studies according to the PEDro scale is presented in Table 4.

Table 3 The basic data on studies included in the analyses

\begin{tabular}{lclcccccc}
\hline \multicolumn{1}{c}{ Study } & Year & Country & $\begin{array}{c}\text { Duration } \\
\text { (weeks) }\end{array}$ & Settings & N & $\begin{array}{c}\text { Mean } \\
\text { Age }\end{array}$ & $\begin{array}{c}\text { Females } \\
(\%)\end{array}$ & $\begin{array}{c}\text { Main } \\
\text { Outcome }\end{array}$ \\
\hline Arcoverde & 2014 & Brazil & 16 & H & 20 & 78.5 & 60 & MMSE \\
Arrieta & 2020 & Spain & 36 & $\mathrm{~N}$ & 88 & 84.8 & 71 & MoCA \\
Bademli & 2018 & Turkey & 20 & $\mathrm{~N}$ & 60 & 72.2 & 60 & MMSE \\
Bossers & 2015 & Netherlands & 9 & $\mathrm{~N}$ & 109 & 85.5 & 78 & MMSE \\
Cancela & 2016 & Spain & 60 & $\mathrm{H}$ & 114 & 80.6 & 43 & MMSE \\
de Souto Barreto & 2017 & France & 24 & $\mathrm{~N}$ & 91 & 88.3 & 93 & MMSE \\
Dorner & 2007 & Austria & 10 & LTC & 30 & 86.8 & 77 & MMSE \\
Enette & 2020 & France & 9 & HoS & 52 & 77.0 & 65 & MMSE \\
Fiatarone & 2014 & Australia & 26 & $\mathrm{H}$ & 49 & - & - & ADAS-Cog \\
Harris & 2017 & Canada & 12 & LTC & 16 & 83.3 & 63 & MMSE \\
Henskens & 2018 & Netherlands & 26 & $\mathrm{~N}$ & 44 & 85.1 & 77 & MMSE \\
Holthoff & 2015 & Germany & 12 & $\mathrm{H}$ & 30 & 72.4 & 53 & MMSE \\
Hong & 2018 & South Korea & 12 & $\mathrm{H}$ & 22 & 77.2 & 73 & MOCA \\
Cheng & 2014 & Hong Kong & 12 & $\mathrm{~N}$ & 74 & 81.8 & 64 & MMSE \\
Christofoletti & 2008 & Brazil & 26 & $\mathrm{~N}$ & 37 & 72.9 & 71 & MMSE \\
Kemoun & 2010 & France & 15 & $\mathrm{~N}$ & 31 & 81.8 & 73 & ERFC \\
Kwak & 2008 & South Korea & 12 & $\mathrm{H}$ & 30 & 79.7 & 100 & MMSE \\
Lam & 2015 & Hong Kong & 52 & $\mathrm{H}$ & 278 & 75.5 & 77 & MMSE \\
Lamb & 2018 & UK & 26 & Hos & 443 & 77.0 & 55 & ADAS-Cog \\
Langoni & 2018 & Brazil & 24 & $\mathrm{H}$ & 52 & 72.6 & 77 & MMSE \\
Lautenschlager & 2008 & Australia & 24 & $\mathrm{H}$ & 170 & 68.7 & 50 & ADAS-Cog \\
Miu & 2008 & Hong Kong & 12 & $\mathrm{H}$ & 85 & 75.0 & 53 & MMSE \\
Mollinedo Cardalda & 2019 & Spain & 12 & $\mathrm{~N}$ & 77 & 85.4 & 70 & MMSE \\
Muscari & 2009 & Italy & 52 & $\mathrm{H}$ & 120 & 69.6 & 50 & MMSE \\
& & & & & & & &
\end{tabular}




\begin{tabular}{lllcccccc}
\hline \multicolumn{1}{c}{ Study } & Year & Country & $\begin{array}{c}\text { Duration } \\
\text { (weeks) }\end{array}$ & Settings & N & $\begin{array}{c}\text { Mean } \\
\text { Age }\end{array}$ & $\begin{array}{c}\text { Females } \\
\text { (\%) }\end{array}$ & $\begin{array}{c}\text { Main } \\
\text { Outcome }\end{array}$ \\
\hline Nascimento & 2015 & Brazil & 26 & H & 45 & 66.7 & 80 & MoCA \\
Qi & 2019 & China & 12 & H & 32 & 70.6 & 69 & MMSE \\
Sanders & 2020 & Netherlands & 24 & H & 69 & 81.7 & 54 & MMSE \\
Siu & 2018 & China & 16 & H & 160 & 77.7 & 75 & MMSE \\
Song & 2019 & China & 16 & H & 120 & 75.8 & 75 & MoCA \\
Sun & 2015 & China & 26 & H & 138 & 68.3 & 81 & MMSE \\
Tao & 2019 & China & 24 & H & 57 & 65.5 & 68 & MoCA \\
Toots & 2017 & Sweden & 16 & N & 166 & 84.4 & 75 & MMSE \\
Van de Winckel & 2004 & Belgium & 6 & Hos & 25 & 81.3 & 100 & MMSE \\
Varela & 2012 & Spain & 12 & N & 48 & 76.2 & 56 & MMSE \\
Venturelli & 2011 & Italy & 26 & N & 24 & 83.0 & 83 & MMSE \\
Vreugdenhil & 2012 & Australia & 16 & H & 40 & 73.5 & 45 & MMSE \\
Wei & 2014 & China & 26 & N & 60 & 66.7 & 30 & MMSE \\
Williamson & 2009 & US & 52 & H & 102 & 76.8 & 72 & MMSE \\
Yang & 2015 & China & 12 & Hos & 50 & 72.6 & 60 & MMSE \\
Yoon & 2017 & South Korea & 12 & H & 30 & 75.0 & 100 & MMSE \\
\hline
\end{tabular}

Note: MMSE - Mini-Mental State Examination; ERFC - Rapid Evaluation of Cognitive Function; ADAS-Cog - Alzheimer Disease Assessment Scale-Cognitive Subscale; MoCA - Montreal Cognitive Assessment; $\mathrm{H}$ - home; $\mathrm{N}$ - nursing home; Hos - hospital; LTC - long-term care facility.

Many types of exercise such walking, cycling, exercising with pneumatic resistance machines or therabands were used in the studies. Altogether $62.5 \%$ of control groups were enrolled in some additional activities such as education, one-to-one conversation, handicrafts, drinking tea with the nursing staff, watching videos or recreational activities. The other participants in the control groups were instructed to maintain their normal physical activities, or they were given standard care in nursing homes. The shortest session was only 15 minutes and the longest was 75 minutes, 60 minutes was the most usual $(19 \times)$. The frequency of exercise program started at 2 sessions a week, and 3 sessions a week was the most frequent $(21 \times)$. Four intervention programs required participants to exercise daily. Descriptions of intervention and control groups included in the review are presented in Table 5.

When we divided interventions according to cognitive impairment severity, duration of program, frequency of program, type of exercise, and activities in control groups we created 27 different categories. In general, $37.0 \%$ of intervention groups presented a statistically significant beneficial effect of physical activity, while only two presented a statistically significant harmful effect on cognitive functions. Nevertheless, $40.0 \%$ of control groups showed a significant decrease in cognitive functions and no group showed an increase. $54.3 \%$ of interventions had a statistically significant beneficial effect (Hedges' g significantly $>0$ ). No intervention demonstrated a statistically significant harmful effect (Hedges' g significantly $<0$ ). A statistically significant bene- 


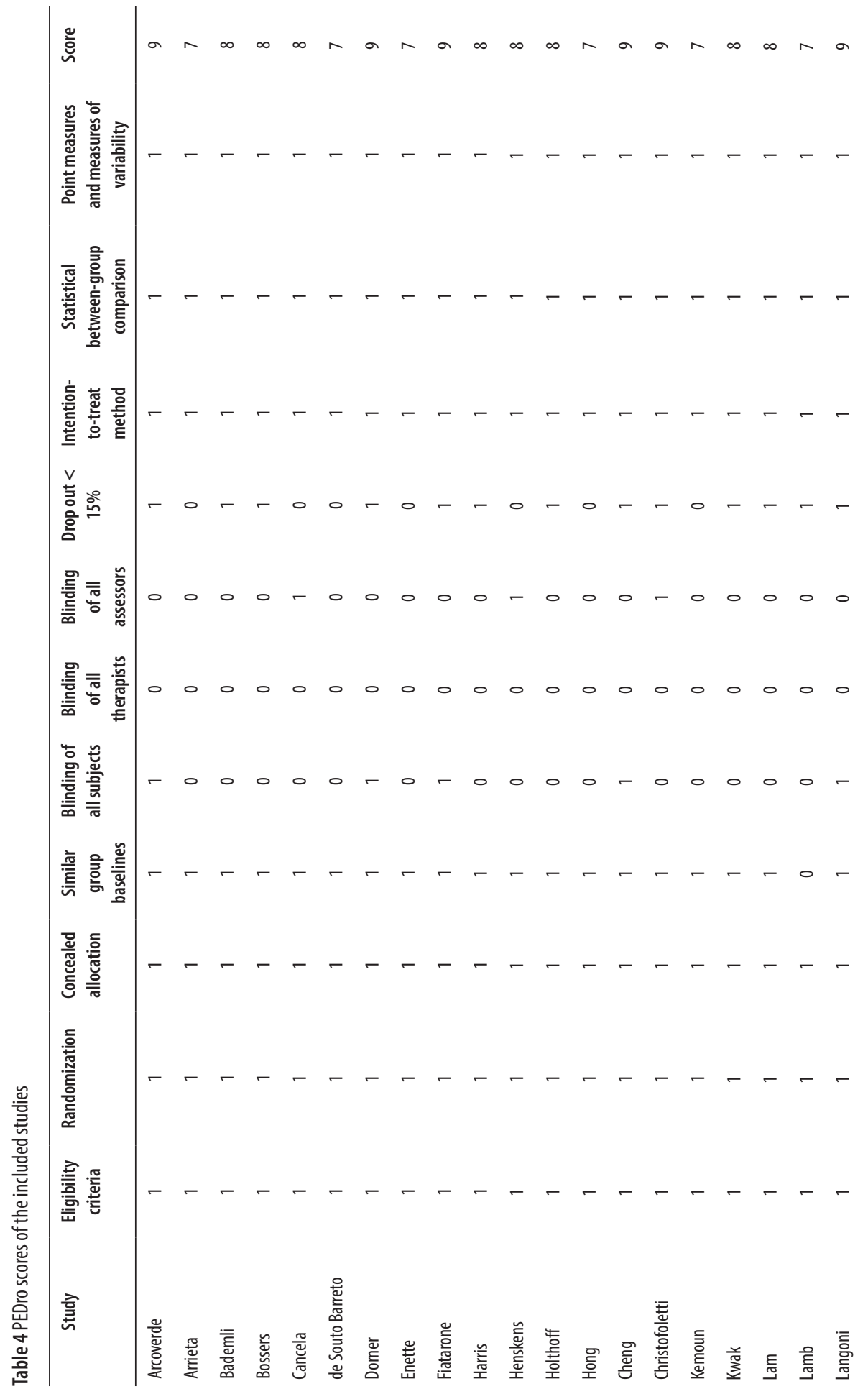




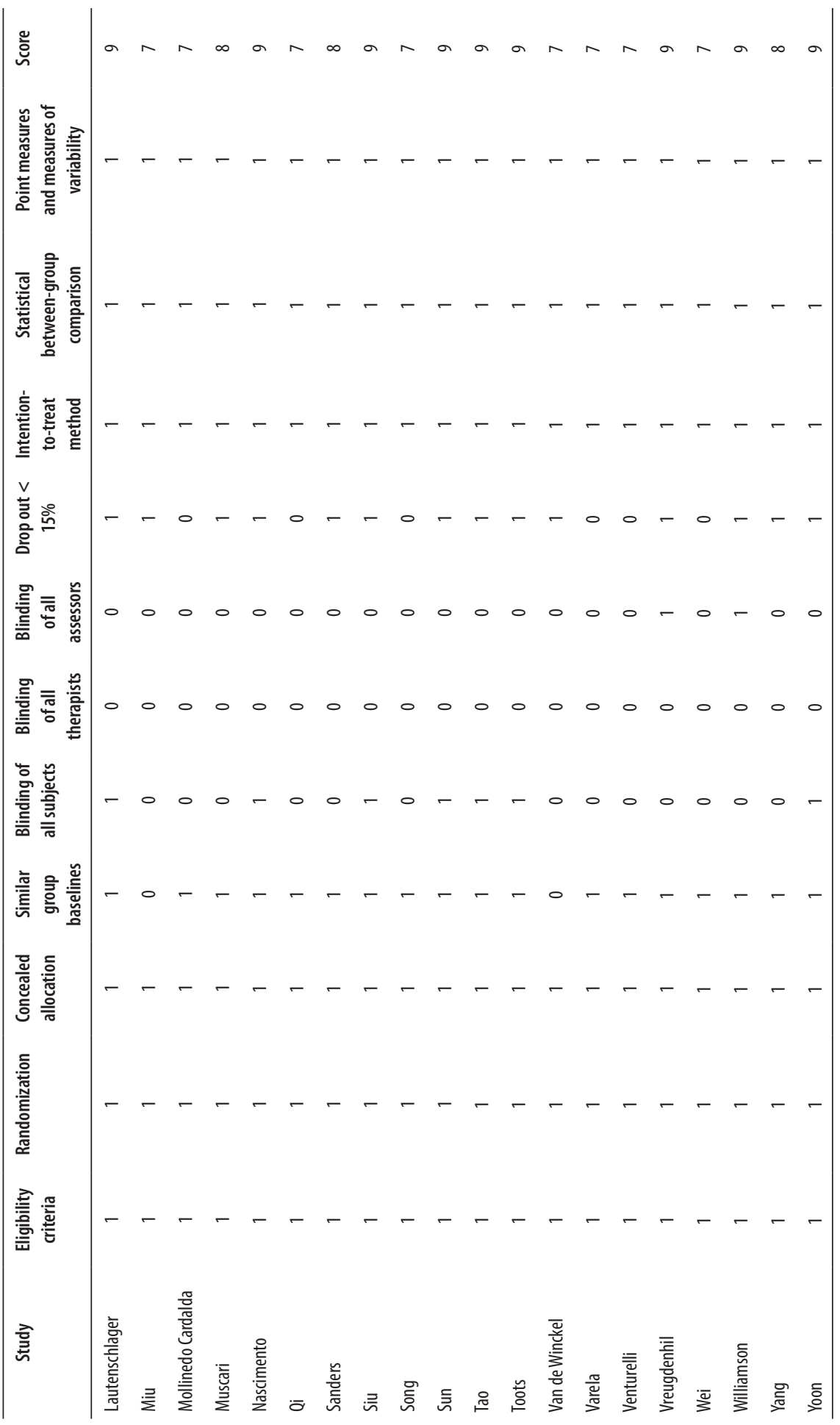




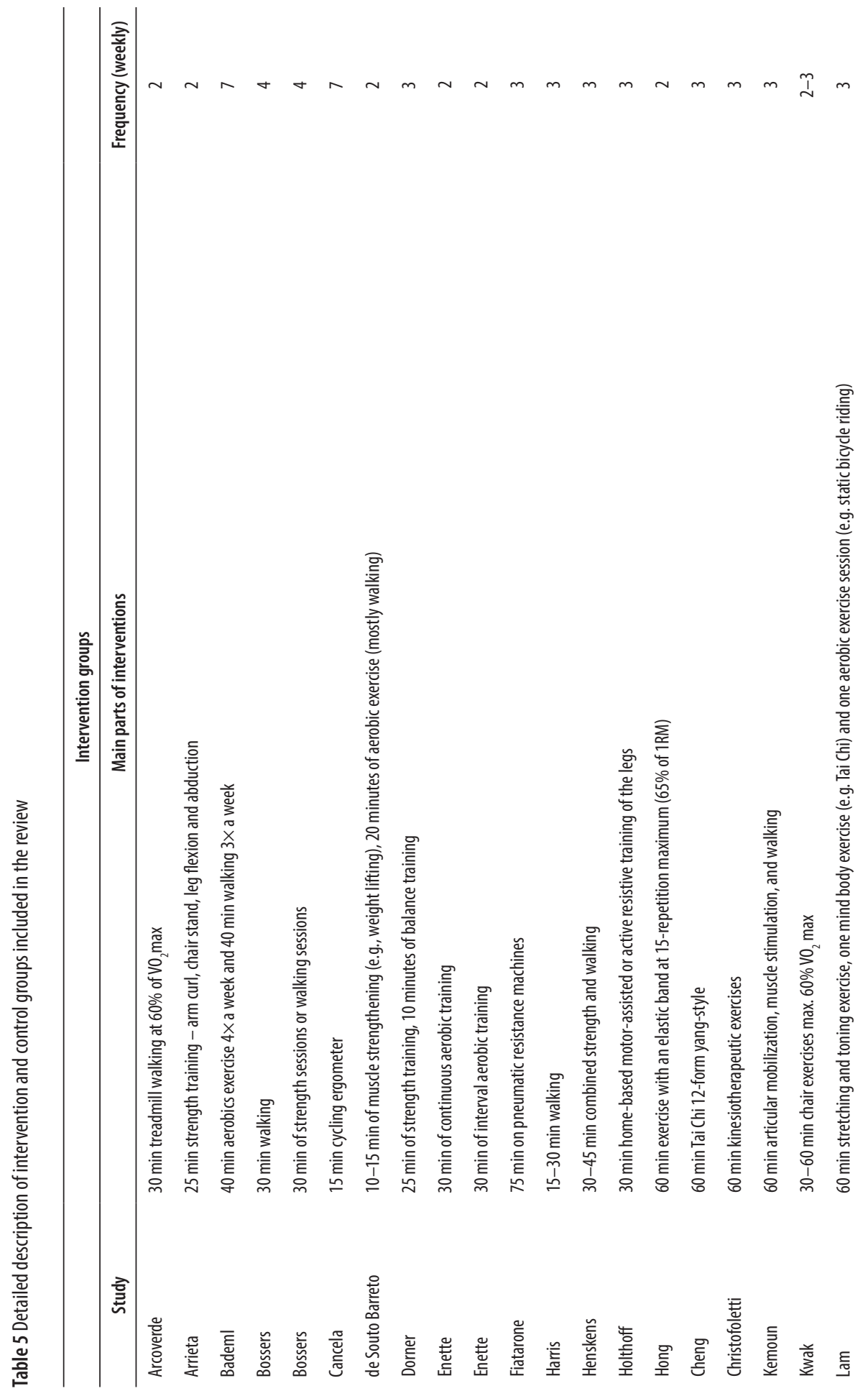




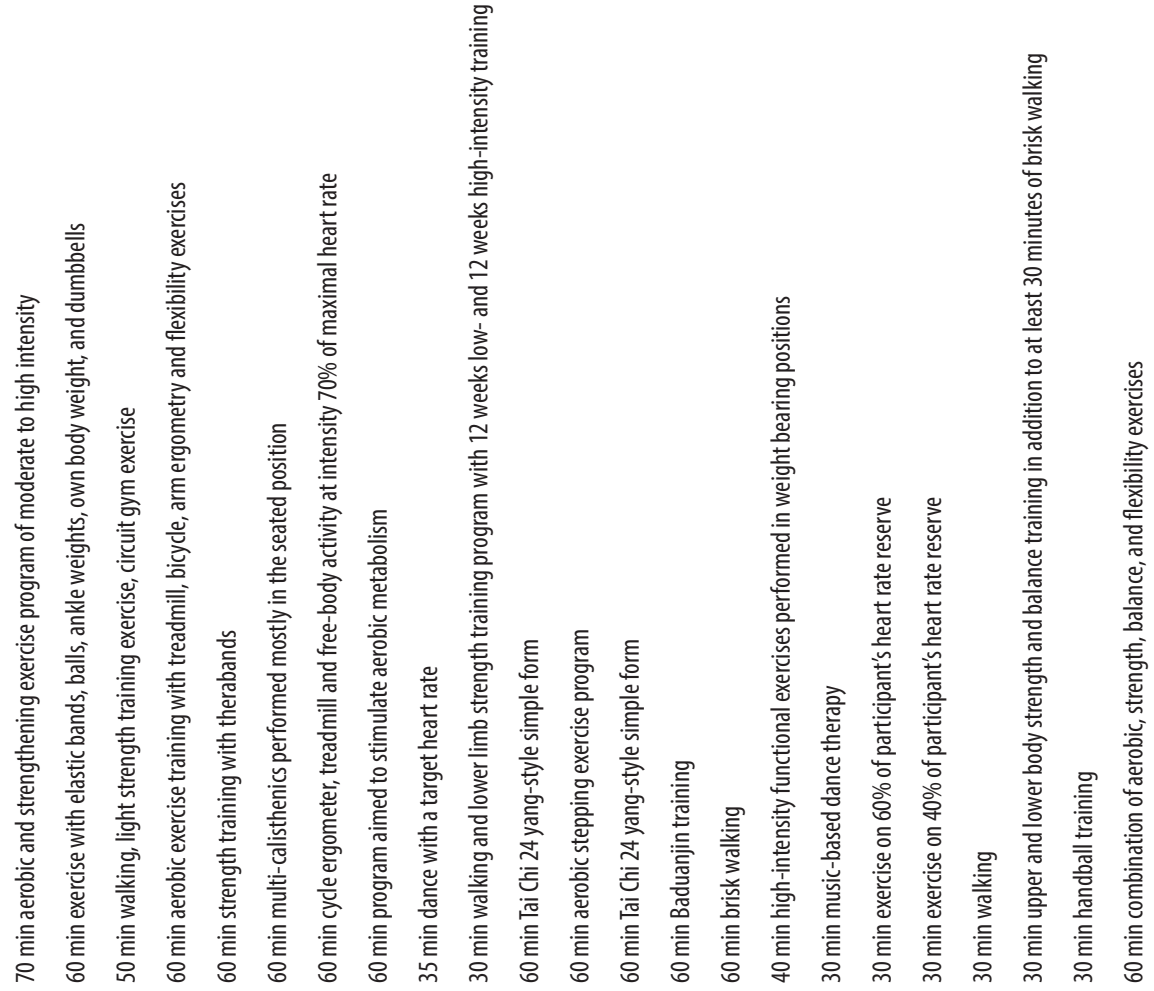

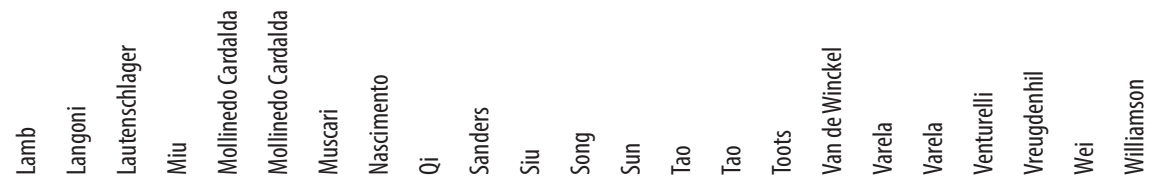




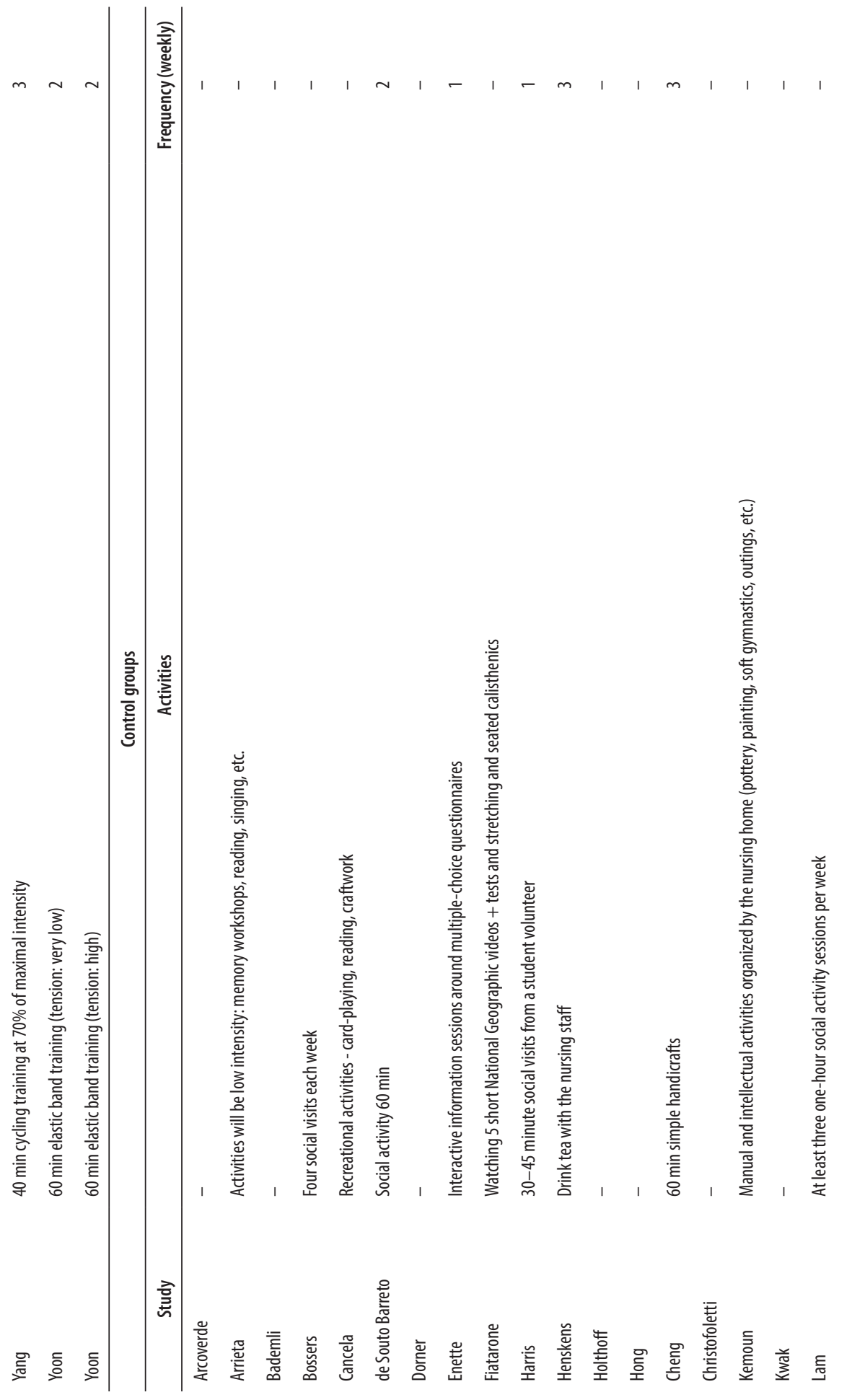




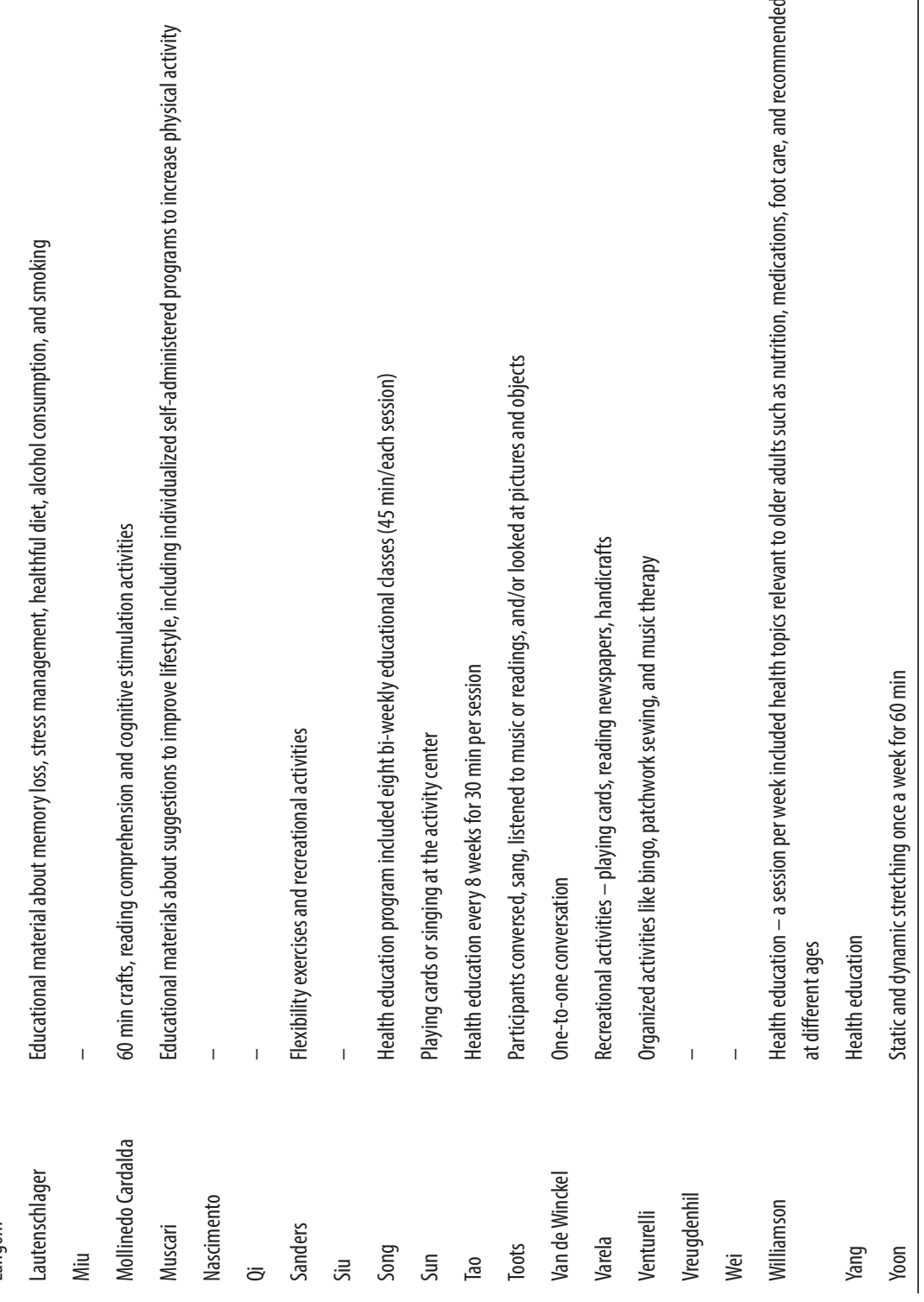




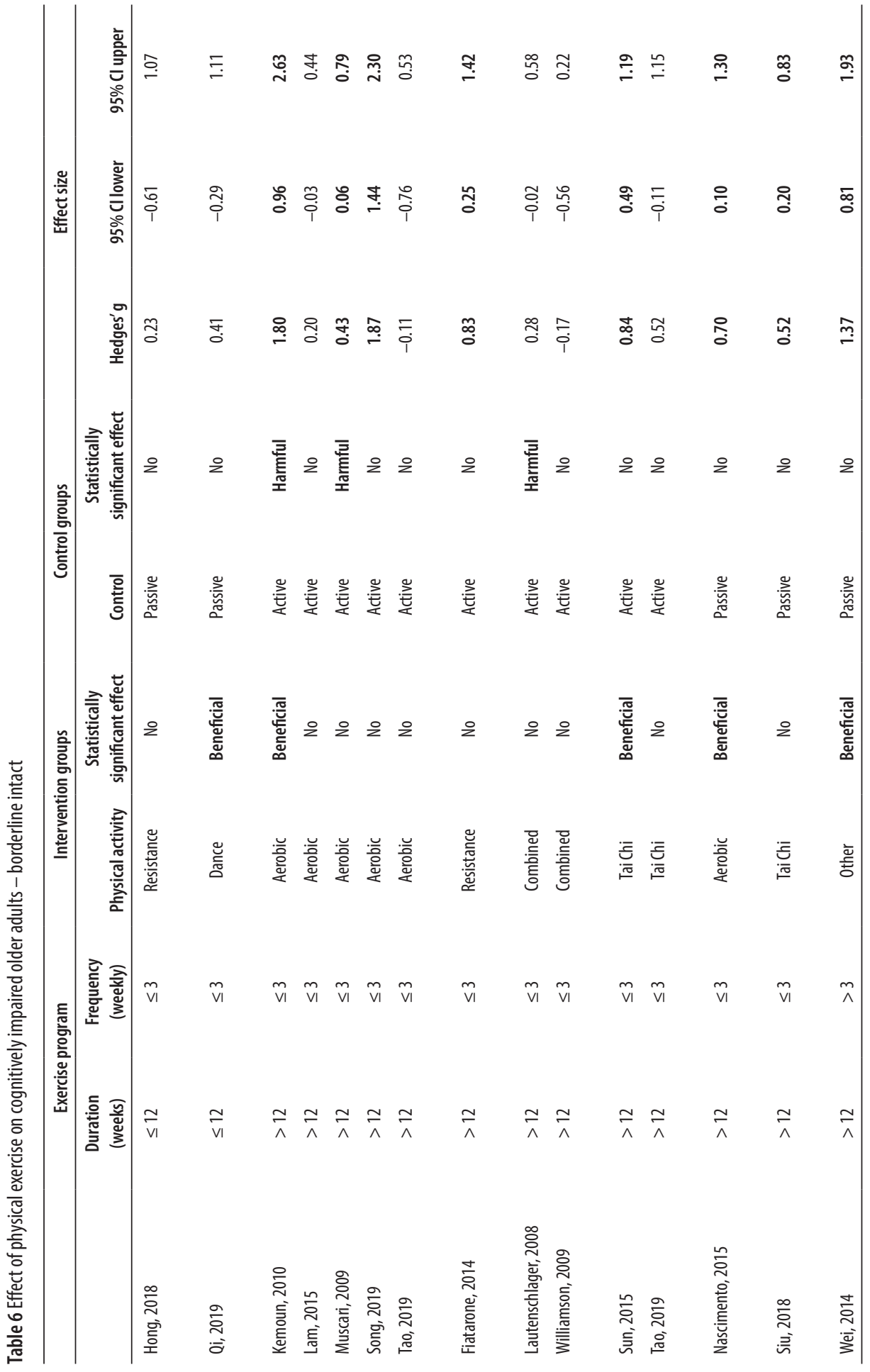




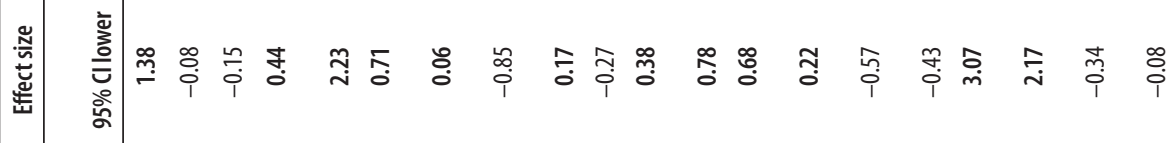

竎

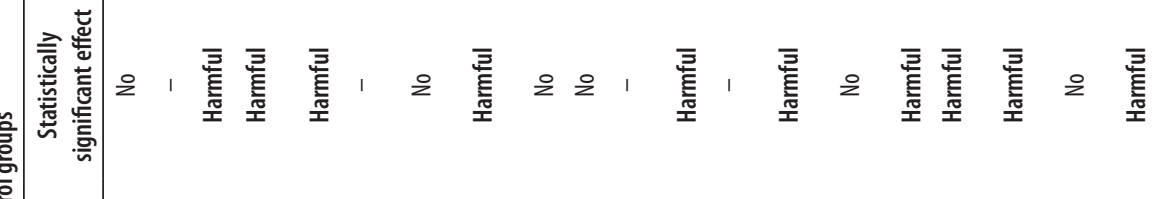

흔

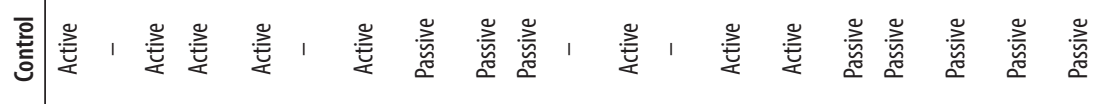

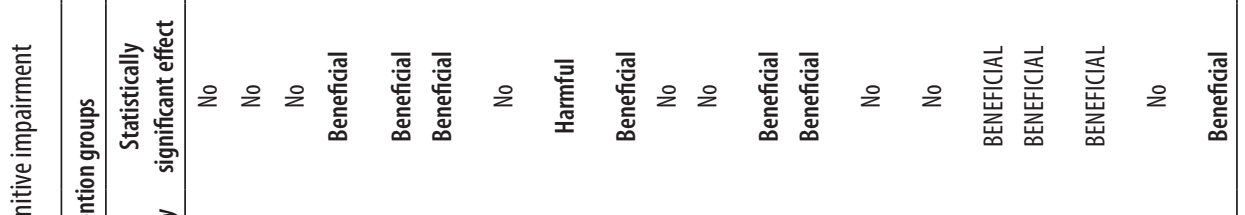

흥

$\frac{\bar{t}}{0}$

竞

竞

產

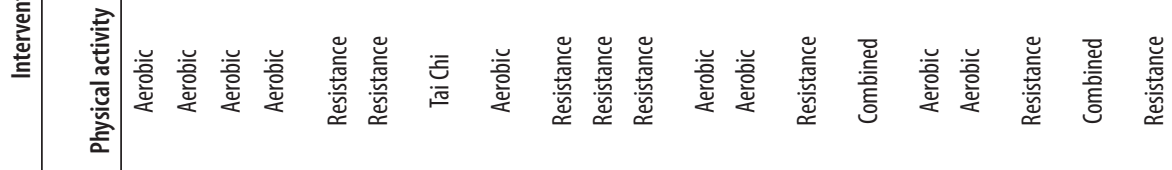

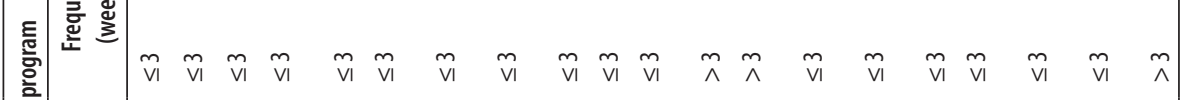

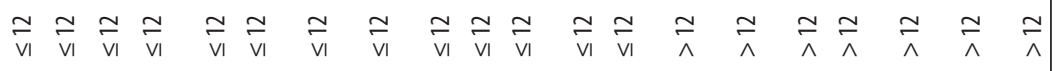

$\stackrel{\text { 응 }}{\text { 定 }}$

亏े

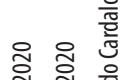

$\frac{\pi}{\frac{\pi}{0}}$

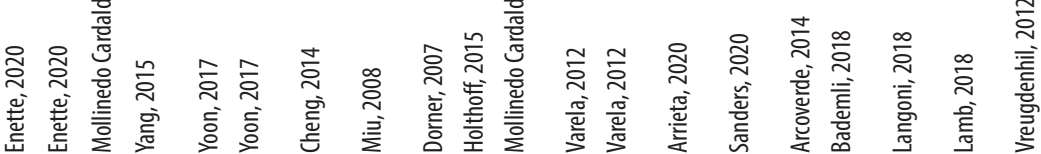




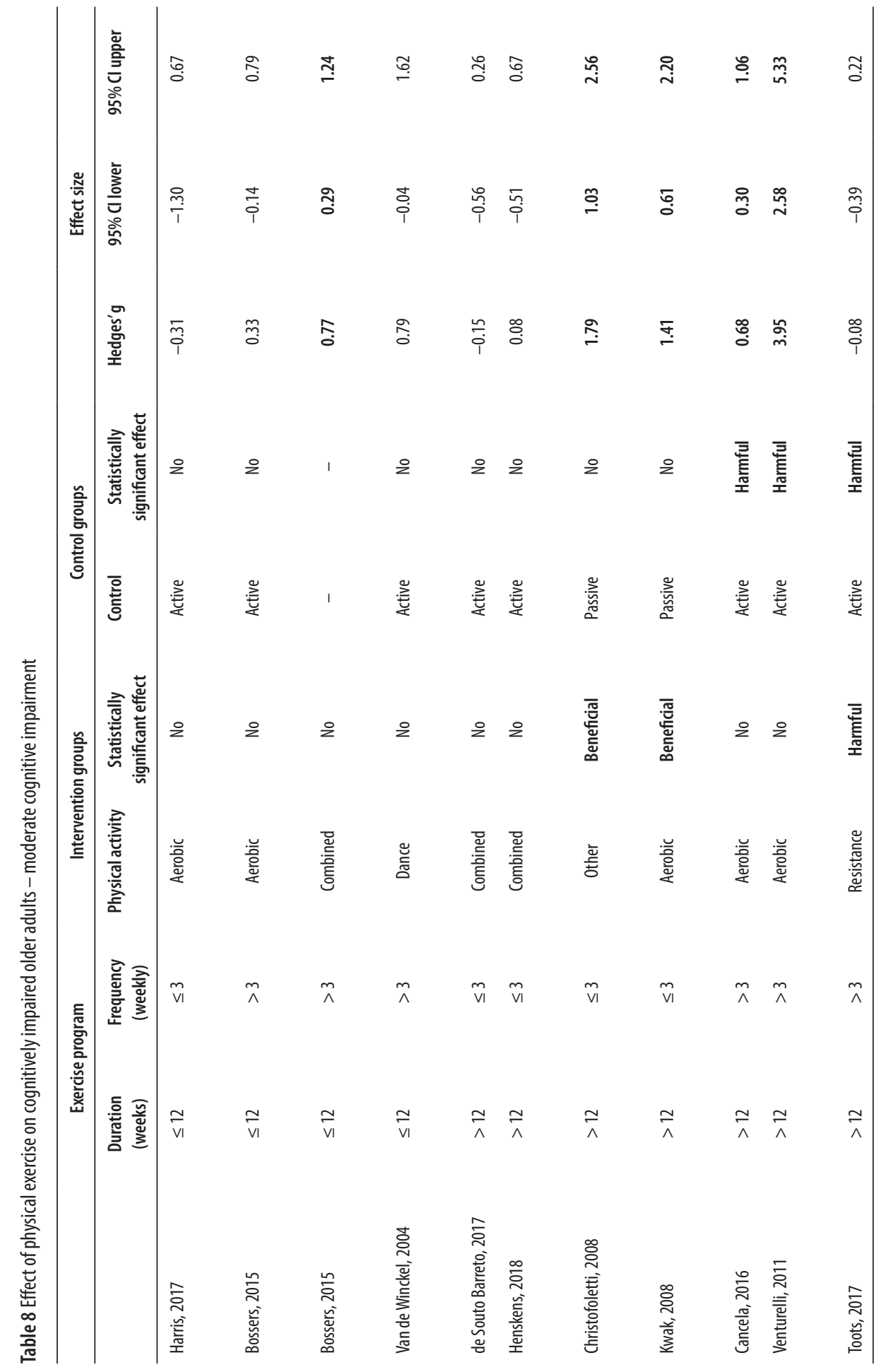


ficial effect was found in: $52.7 \%$ of interventions with frequency $\leq 3$ sessions weekly, $60 \%$ of interventions with frequency $>3$ sessions weekly, $61.1 \%$ of aerobic exercise, $63.3 \%$ of resistance exercise, $35.3 \%$ of other exercise interventions, $50 \%$ of bordeline intact participants, $60 \%$ of participants with mild cognitive impairment, and $45.5 \%$ of participants with moderate cognitive impairment. The highest effect was found in Bademli (Bademli et al., 2018) in participants with mild cognitive impairment where the duration was $>12$ with frequency $\leq 3$ of aerobic exercise against a passive control Hedges' $g=3.82$ (95\% CI 2.97-4.67). On the other hand, an almost statistically significant harmful effect was found in the Miu study (Miu et al., 2008) with a similar design where the only difference was in the duration that was $\leq 12$ weeks Hedges' $g=-0.41$ (95\% CI $-0.84-0.03)$. The effect of physical exercise on cognitively impaired older adults according to impairment severity is presented in Tables 6, 7 and 8.

\section{DISCUSSION}

It is well-established that cognitive functions decline gradually over time as part of the natural ageing process (Harada et al., 2013). The findings of this systematic review partly indicate that physical exercise may have the power to mitigate the cognitive decline process even in people with cognitive impairment. The similar findings were found in previous reviews where physical exercise had a positive effect on executive function (Gates et al., 2013; Song et al., 2018), and on global cognition (Groot et al., 2016; Wang et al., 2014; Ohman, 2014) in individuals with mild cognitive impairment. However, the new knowledge from this study is that the positive effect is stronger in people with a mild level of cognitive impairment and, above all, it points to a very strong negative effect of physical inactivity on cognitive function in the control groups.

However, it was practically impossible to merge the studies together into one analysis because so many different approaches were used regarding physical exercise activities, control group activities as well as the frequency of exercise program. Studies included in this review varied in terms of duration of exercise programs. In twentyseven studies, the duration of interventions was less than half a year, and in another nineteen, the duration of the interventions was for more than or equal to half a year. According to our analysis, it seems that the duration of the exercise program was associated with cognitive decline, which may be caused by the natural cognitive decline during ageing. Surprisingly, the frequency of exercise per week did not play any significant role in global cognition.

It has been well described that the positive effect of aerobic exercise on brain health lies in the mechanisms behind aerobic exercise such as neovascularization, synaptogenesis and angiogenesis, hippocampal high-affinity choline uptake and upregulation of muscarinic receptor density, increasing of mitochondrial volume in Purkinje cells, inhibition of the apoptotic biochemical cascades, identified primarily through animal research (Black et al., 1990; Fordyceet al., 1991; Isaacs et al., 1992; Um et al., 2008).

Moreover, a higher number of female participants in intervention groups experienced a positive effect on global cognitive function. This result could be explained by both different cognitive responses to exercise between men and women as well as by the different ratios in elderly females suffering dementia. As described by Baker et al. (2010), aerobic exercise improved performance on multiple tests of executive 
function, increased glucose disposal during the metabolic clamp, and reduced fasting plasma levels of insulin, cortisol, and brain-derived neurotrophic factor in women but not in men (Baker et al., 2010). They also found that peak oxygen consumption was associated with improved executive function in women. It turns out that gender differences in cognitive functions can be related to the metabolic effects of physical activity. However, there are several other reasons why gender may influence trial results. For instance, women have a higher lifetime risk of dementia (Chene et al., 2015), greater vulnerability to certain risk factors such as gender-specific chromosomes, APOE $\varepsilon 4$, gender differences in hormone levels etc. (Snyder et al., 2016), and they demonstrate higher differential associations between biomarkers and cognitive impairment than men (Koran et al., 2017). Moreover, there was a higher percentage of female participants in the intervention studies ( 32 of 36 intervention groups had a majority of female participants). One reason for this fact could be higher life expectancy in females (Samaras et al., 2018) although the gender age gap has been narrowing in Europe recently (Kolip \& Lange, 2018). Another explanation could be greater adherence to health-related exercise programs in older women (Aartolahti et al., 2015). Thus, it would be of interest to explain which of the above-mentioned proposed factors is responsible for gender differences.

It should be noted that one of the biggest limitations of this study was considerable heterogeneity in all the analyses which hampered the meta-analysis. In fact, heterogeneity is a common problem of meta-analyses on this topic (Gates et al., 2013; Ohman et al., 2014). Moreover, it was almost impossible to create a category with similar cognitive impairment because it varied considerably among the studies so the classification has some limitations, because if the variability was high then we could not be sure that all the participants were allocated correctly. The same is true for exercise interventions because the interventions included many different activities with different durations and intensities.

\section{CONCLUSION}

Despite the numerous limitations mentioned above, this study has shown that physical exercise may have the power to influence cognitive functions in people with cognitive impairment especially in people with a mild level of cognitive impairment. Such findings could have practical implications for recommending physical activity as a nonpharmacologic treatment to combat the progression of cognitive decline in patients with dementia. Future research based on longitudinal epidemiological studies is needed to confirm such findings further.

\section{List of abbreviations}

$\begin{array}{ll}\text { ADAS-Cog } & \text { Alzheimer Disease Assessment Scale-Cognitive Subscale } \\ \text { B } & \text { Standardized Coefficient Beta } \\ \text { CAMCOG } & \text { Cambridge Cognitive Examination } \\ \text { CI } & \text { Confidence Interval } \\ \text { ERFC } & \text { Rapid Evaluation of Cognitive Function } \\ \text { MMSE } & \text { Mini Mental State Examination } \\ \text { MoCA } & \text { Montreal Cognitive Assessment }\end{array}$


PRISMA Preferred Reporting Items for Systematic Reviews and Meta-Analyses PEDro Physiotherapy Evidence Database

RCT Randomized Control Trials

SE Standard Error

SMD Standardized Mean Difference

$\mathrm{VO}_{2 \max } \quad$ the maximum amount of oxygen the body can utilize during a specified period of usually intense exercise

WA Weighted Averages

\section{DECLARATIONS}

\section{Ethics approval and consent to participate}

$\mathrm{N} / \mathrm{A}$

\section{Consent for publication}

$\mathrm{N} / \mathrm{A}$

\section{Availability of supporting data and material}

The datasets used and/or analyzed during the current study are available from the corresponding author on reasonable request.

\section{Competing interests}

This manuscript has not been previously submitted or published and is not under consideration in any other peer-reviewed media. To the best of our knowledge, no conflict of interest, financial or other, exists.

\section{Funding}

This research was supported by the Alzheimer Endowment Fund - AVAST, the project Q41, the AZV research project NV18-09-00587 of the Ministry of Health and project SVV 260466.

The funding agencies played no role in study design, data collection and analysis, decision to publish, or preparation of the manuscript.

\section{Authors' contribution}

$\mathrm{LS}, \mathrm{AB}$, and MS have screened the literature and selected papers for inclusion in the review. LS, MS, KD, and $\mathrm{IH}$ have contributed to data extraction. All authors read and approved the final manuscript.

\section{ACKNOWLEDGEMENTS}

$\mathrm{N} / \mathrm{A}$ 


\section{REFERENCES}

Aartolahti, E., Tolppanen, A. M., Lonnroos, E., Hartikainen, S., Hakkinen, A. (2015). Health condition and physical function as predictors of adherence in long-term strength and balance training among community-dwelling older adults. Archives of Gerontology and Geriatrics, 61(3), 452-457.

Arcoverde, C., Deslandes, A., Moraes, H., Almeida, C., de Araujo, N. B., Vasques, P. E., Silveira, H., Laks, J. (2014). Treadmill training as an augmentation treatment for Alzheimer's disease: A pilot randomized controlled study. Arquivos de Neuro-Psiquiatria, 72(3), 190-196.

Arrieta, H., Rezola-Pardo, C., Kortajarena, M., Hervas, G., Gil, J., Yanguas, J. J., Iturburu, M., Gil, S. M., Irazusta, J., Rodriguez-Larrad, A. (2020). The impact of physical exercise on cognitive and affective functions and serum levels of brain-derived neurotrophic factor in nursing home residents: A randomized controlled trial. Maturitas, 131(3), 72-77.

Bademli, K., Lok, N., Canbaz, M., Lok, S. (2019). Effects of Physical Activity Program on cognitive function and sleep quality in elderly with mild cognitive impairment: A randomized controlled trial. Perspect Psychiatr Care, 55(3), 401-408.

Baker, L. D., Frank, L. L., Foster-Schubert, K., Green, P. S., Wilkinson, C. W., McTiernan, A., Plymate, S. R., Fishel, M. A., Watson, G. S., Cholerton, B. A. et al. (2010). Effects of aerobic exercise on mild cognitive impairment: a controlled trial. Archives of Neurology, 67(1), 71-79.

Black, J. E., Isaacs, K. R., Anderson, B. J., Alcantara, A. A., Greenough, W. T. (1990). Learning causes synaptogenesis, whereas motor activity causes angiogenesis, in cerebellar cortex of adult rats Proceedings of the National Academy of Sciences of the USA, 87(14), 5568-5572.

Blondell, S. J., Hammersley-Mather, R., Veerman, J. L. (2014). Does physical activity prevent cognitive decline and dementia?: A systematic review and meta-analysis of longitudinal studies. BMC Public Health, 14(1), 510.

Bossers, W. J., van der Woude, L. H., Boersma, F., Hortobagyi, T., Scherder, E. J., van Heuvelen, M. J. (2015). A 9-week aerobic and strength training program improves cognitive and motor function in patients with dementia: A randomized, controlled trial. The American Journal of Geriatric Psychiatry, 23(11), 1106-1116.

Cancela, J. M., Ayan, C., Varela, S., Seijo, M. (2016). Effects of a long-term aerobic exercise intervention on institutionalized patients with dementia. Journal of Science and Medicine in Sport, 19(4), 293-298.

de Souto Barreto, P., Cesari, M., Denormandie, P., Armaingaud, D., Vellas, B., Rolland, Y. (2017). Exercise or social intervention for nursing home residents with dementia: A pilot randomized, controlled trial. Journal of the American Geriatrics Society, 65(9), E123-E129.

Dorner, T., Kranz, A., Zettl-Wiedner, K., Ludwig, C., Rieder, A., Gisinger, C. (2007). The effect of structured strength and balance training on cognitive function in frail, cognitive impaired elderly long-term care residents. Aging clinical and experimental research, 19(5), 400-405.

Enette, L., Vogel, T., Merle, S., Valard-Guiguet, A. G., Ozier-Lafontaine, N., Neviere, R., Leuly-Joncart, C., Fanon, J. L., Lang, P. O. (2020). Effect of 9 weeks continuous vs. interval aerobic training on plasma BDNF levels, aerobic fitness, cognitive capacity and quality of life among seniors with mild to moderate Alzheimer's disease: a randomized controlled trial. European Review of Aging and Physical Activity, 17, 2.

Fiatarone Singh, M. A., Gates, N., Saigal, N., Wilson, G. C., Meiklejohn, J., Brodaty, H., Wen, W., Singh, N., Baune, B. T., Suo, C. et al. (2014). The Study of Mental and Resistance Training (SMART) study-resistance training and/or cognitive training in mild cognitive impairment: a randomized, double-blind, double-sham controlled trial. Journal of the American Medical Directors Association, 15(12), 873-880. 
Folstein, M. F., Robins, L. N., Helzer, J. E. (1983). The mini-mental state examination. Archives of General Psychiatry, 40(7), 812.

Forbes, D., Forbes, S. C., Blake, C. M., Thiessen, E. J., Forbes, S. (2015). Exercise programs for people with dementia. Cochrane Database Syst. Rev., Apr. 15, (4).

Fordyce, D. E., Farrar, R. P. (1991). Enhancement of spatial learning in F344 rats by physical activity and related learning-associated alterations in hippocampal and cortical cholinergic functioning. Behavioural Brain Research, 46(2), 123-133.

Garuffi, M., Costa, J. L., Hernandez, S. S., Vital, T. M., Stein, A. M., dos Santos, J. G., Stella, F. (2013). Effects of resistance training on the performance of activities of daily living in patients with Alzheimer's disease. Geriatrics \& Gerontology International, 13(2), 322-328.

Gates, N., Fiatarone Singh, M. A., Sachdev, P. S., Valenzuela, M. (2013). The effect of exercise training on cognitive function in older adults with mild cognitive impairment: a meta-analysis of randomized controlled trials. American Journal of Geriatric Psychiatry, 21(11), 1086-1097.

Gil, R., Toullat, G., Pluchon, C., Micheneau, D., Cariou, B., Rivault, L., Sicot, I., Boissonnot, L. (1986). Une méthode d'évaluation rapide des fonctions cognitives (ERFC), son application à la démence sénile de type Alzheimer. Semin Hop Paris, 62(27), 2127-2133.

Groot, C., Hooghiemstra, A. M., Raijmakers, P. G., van Berckel, B. N., Scheltens, P., Scherder, E. J., van der Flier, W. M., Ossenkoppele, R. (2016). The effect of physical activity on cognitive function in patients with dementia: A meta-analysis of randomized control trials. Ageing Research Reviews, Jan, 25, 13-23.

Harada, C. N., Natelson Love, M. C., Triebel, K. L. (2013). Normal cognitive aging. Clin. Geriatr. Med., 29(4), 737-752.

Harris, J. B., Johnson, C. S. (2017). The Impact of Physical versus Social Activity on the Physical and Cognitive Functioning of Seniors with Dementia. Act. Adapt. Aging, 41(2), 161-174.

Hauer, K., Schwenk, M., Zieschang, T., Essig, M., Becker, C., Oster, P. (2012). Physical training improves motor performance in people with dementia: a randomized controlled trial. . Journal of the American Geriatrics Society, 60(1), 8-15.

Hedges, L. (1981). Distribution Theory for Glass's Estimator of Effect Size and Related Estimators. J. Educ. Behav. Stat., 6(2), 107-128.

Henskens, M., Nauta, I. M., Van Eekeren, M. C. A., Scherder, E. J. A. (2018). Effects of Physical Activity in Nursing Home Residents with Dementia: A Randomized Controlled Trial. Dementia and Geriatric Cognitive Disorders, 46(1-2), 60-80.

Higgins, J. P. T., Thomas, J., Chandler, J., Cumpston, M., Li, T., Page, M. J., Welch, V. A. (2019). Cochrane Handbook for Systematic Reviews of Interventions. 2nd Edition. Chichester (UK): John Wiley \& Sons.

Holthoff, V. A., Marschner, K., Scharf, M., Steding, J., Meyer, S., Koch, R., Donix, M. (2015). Effects of physical activity training in patients with Alzheimer's dementia: results of a pilot RCT study. PLoS One, 10(4), e0121478.

Hong, S. G., Kim, J. H., Jun, T. W. (2018). Effects of 12-Week Resistance Exercise on Electroencephalogram Patterns and Cognitive Function in the Elderly With Mild Cognitive Impairment: A Randomized Controlled Trial. Clinical Journal of Sport Medicine, 28(6), 500-508.

Chen, W. W., Zhang, X., Huang, W. J. (2016). Role of physical exercise in Alzheimer's disease. Biomedical Reports, 4(4), 403-407.

Chene, G., Beiser, A., Au, R., Preis, S. R., Wolf, P. A., Dufouil, C., Seshadri, S. (2015). Gender and incidence of dementia in the Framingham Heart Study from mid-adult life. The Journal of the Alzheimer's Association, 11(3), 310-320. 
Cheng, S. T., Chow, P. K., Song, Y. Q., Yu, E. C., Chan, A. C., Lee, T. M., Lam, J. H. (2014). Mental and physical activities delay cognitive decline in older persons with dementia. The American Journal of Geriatric Psychiatry, 22(1), 63-74.

Christofoletti, G., Oliani, M. M., Gobbi, S., Stella, F., Bucken Gobbi, L. T., Renato Canineu, P. (2008). A controlled clinical trial on the effects of motor intervention on balance and cognition in institutionalized elderly patients with dementia. Clinical Rehabilitation, 22(7), 618-626.

Isaacs, K. R., Anderson, B. J., Alcantara, A. A., Black, J. E., Greenough, W. T. (1992). Exercise and the brain: angiogenesis in the adult rat cerebellum after vigorous physical activity and motor skill learning. Journal of Cerebral Blood Flow \& Metabolism, 12(1), 110-119.

Kemoun, G., Thibaud, M., Roumagne, N., Carette, P., Albinet, C., Toussaint, L., Paccalin, M., Dugue, B. (2010). Effects of a physical training programme on cognitive function and walking efficiency in elderly persons with dementia. Dementia and Geriatric Cognitive Disorders, 29(2), 109-114.

Kolip, P., Lange, C. (2018). Gender inequality and the gender gap in life expectancy in the European Union. European Journal of Public Health, 28(5), 869-872.

Koran, M. E. I., Wagener, M., Hohman, T. J. (2017). Alzheimer's Neuroimaging, I. Sex differences in the association between $\mathrm{AD}$ biomarkers and cognitive decline. Brain Imaging Behavior, 11(1), 205-213.

Kwak, Y. S., Um, S. Y., Son, T. G., Kim, D. J. (2008). Effect of regular exercise on senile dementia patients. International Journal of Sports Medicine, 29(6), 471-474.

Lam, L. C., Chan, W. C., Leung, T., Fung, A. W., Leung, E. M. (2015). Would older adults with mild cognitive impairment adhere to and benefit from a structured lifestyle activity intervention to enhance cognition?: a cluster randomized controlled trial. PLoS One, 10(3), e0118173.

Lamb, S. E., Sheehan, B., Atherton, N., Nichols, V., Collins, H., Mistry, D., Dosanjh, S., Slowther, A. M., Khan, I., Petrou, S. et al. (2018). Dementia And Physical Activity (DAPA) trial of moderate to high intensity exercise training for people with dementia: randomised controlled trial. British Medical Journal, 16.

Langoni, C. D. S., Resende, T. L., Barcellos, A. B., Cecchele, B., Knob, M. S., Silva, T. D. N., Rosa, J. N. D., Diogo, T. S., Silva Filho, I. G. D., Schwanke, C. H. A. (2018). Effect of Exercise on Cognition, Conditioning, Muscle Endurance, and Balance in Older Adults With Mild Cognitive Impairment: A Randomized Controlled Trial. Journal of Geriatric Physical Therapy, May 4, 0000000000000191.

Lautenschlager, N. T., Cox, K. L., Flicker, L., Foster, J. K., van Bockxmeer, F. M., Xiao, J. G., Greenop, K. R., Almeida, O. P. (2009). Effect of Physical Activity on Cognitive Function in Older Adults at Risk for Alzheimer Disease: A Randomized Trial. Jama-Journal of the American Medical Association, 301(1), 276-276.

Maher, C. G., Sherrington, C., Herbert, R. D., Moseley, A. M., Elkins, M. (2003). Reliability of the PEDro scale for rating quality of randomized controlled trials. Phys Ther, 83(8), 713-721.

Miu, D., Szeto, S. L., Mak, Y. F. (2008). A randomised controlled trial on the effect of exercise on physical, cognitive and affective function in dementia subjects. Asian Journal of Gerontology \& Geriatrics, 3, 8-16.

Moher, D., Liberati, A., Tetzlaff, J., Altman, D. G., Group, P. (2009). Preferred reporting items for systematic reviews and meta-analyses: the PRISMA statement. PLoS Med., 6(7), e1000097.

Mohs, R. C., Knopman, D., Petersen, R. C., Ferris, S. H., Ernesto, C., Grundman, M., Sano, M., Bieliauskas, L., Geldmacher, D., Clark, C. et al. (1997). Development of cognitive instruments for use in clinical trials of antidementia drugs: additions to the Alzheimer's Disease 
Assessment Scale that broaden its scope. The Alzheimer's Disease Cooperative Study. Alzheimer Disease \& Associated Disorders, 11 (Suppl. 2), S13-21.

Mollinedo Cardalda, I., López, A., Cancela Carral, J. M. (2019). The effects of different types of physical exercise on physical and cognitive function in frail institutionalized older adults with mild to moderate cognitive impairment. A randomized controlled trial. Archives of Gerontology and Geriatrics, 83, 223-230.

Muscari, A., Giannoni, C., Pierpaoli, L., Berzigotti, A., Maietta, P., Foschi, E., Ravaioli, C., Poggiopollini, G., Bianchi, G., Magalotti, D. et al. (2010). Chronic endurance exercise training prevents aging-related cognitive decline in healthy older adults: a randomized controlled trial. International Journal of Geriatric Psychiatry, 25(10), 1055-1064.

Nascimento, C. M., Pereira, J. R., Pires de Andrade, L., Garuffi, M., Ayan, C., Kerr, D. S., Talib, L. L., Cominetti, M. R., Stella, F. (2015). Physical exercise improves peripheral BDNF levels and cognitive functions in mild cognitive impairment elderly with different bdnf Val66Met genotypes. Journal of Alzheimer's Disease, 43(1), 81-91.

Nasreddine, Z. S., Phillips, N. A., Bedirian, V., Charbonneau, S., Whitehead, V., Collin, I., Cummings, J. L., Chertkow, H. (2005). The Montreal Cognitive Assessment, MoCA: a brief screening tool for mild cognitive impairment. Journal of the American Geriatrics Society, 53(4), 695-699.

Ohman, H., Savikko, N., Strandberg, T. E., Pitkala, K. H. (2014). Effect of physical exercise on cognitive performance in older adults with mild cognitive impairment or dementia: a systematic review. Dementia and Geriatric Cognitive Disorders, 38(5-6), 347-365.

Pitkala, K. H., Poysti, M. M., Laakkonen, M. L., Tilvis, R. S., Savikko, N., Kautiainen, H., Strandberg, T. E. (2013). Effects of the Finnish Alzheimer disease exercise trial (FINALEX): a randomized controlled trial. JAMA Internal Medicine, 173(10), 894-901.

Qi, M., Zhu, Y., Zhang, L., Wu, T., Wang, J. (2019). The effect of aerobic dance intervention on brain spontaneous activity in older adults with mild cognitive impairment: A resting-state functional MRI study. Experimental and Therapeutic Medicine, 17(1), 715-722.

Rockwood, K., Middleton, L. (2007). Physical activity and the maintenance of cognitive function. Alzheimer's Dementia, 3(Suppl. 2), S38-44.

Rolland, Y., Abellan van Kan, G., Vellas, B. (2008). Physical Activity and Alzheimer's Disease: From Prevention to Therapeutic Perspectives. Journal of the American Medical Directors Association, 9(6), 390-405.

Roth, M., Huppert, F. A., Mountjoy, C. Q., Tym, E. (1998). CAMDEX-R: The Cambridge Examination for Mental Disorders of the Elderly. Cambridge: Cambridge University Press.

Samaras, T., Marson, S., Lillis, J. (2018). The close inverse relationship between male and female height and life expectancy. Innovation in Aging, 2(Suppl. 1), 888-889.

Sanders, L. M. J., Hortobagyi, T., Karssemeijer, E. G. A., Van der Zee, E. A., Scherder, E. J. A., van Heuvelen, M. J. G. (2020). Effects of low- and high-intensity physical exercise on physical and cognitive function in older persons with dementia: a randomized controlled trial. Alzheimer's Research \& Therapy, 12(1), 28.

Shah, H., Albanese, E., Duggan, C., Rudan, I., Langa, K. M., Carrillo, M. C., Chan, K. Y., Joanette, Y., Prince, M., Rossor, M. et al. (2016). Research priorities to reduce the global burden of dementia by 2025. Lancet Neurology, 15(12), 1285-1294.

Schwenk, M., Zieschang, T., Englert, S., Grewal, G., Najafi, B., Hauer, K. (2014). Improvements in gait characteristics after intensive resistance and functional training in people with dementia: a randomised controlled trial. BMC Geriatrics, 14(1), 73.

Siu, M. Y., Lee, D. T. F. (2018). Effects of tai chi on cognition and instrumental activities of daily living in community dwelling older people with mild cognitive impairment. $B M C$ Geriatrics, $18(1), 37$.

Snyder, H. M., Asthana, S., Bain, L., Brinton, R., Craft, S., Dubal, D. B., Espeland, M. A., Gatz, M., Mielke, M. M., Raber, J. et al. (2016). Sex biology contributions to vulnerability 
to Alzheimer's disease: A think tank convened by the Women's Alzheimer's Research Initiative. Alzheimer's Dementia, 12(11), 1186-1196.

Song, D., Yu, D. S. F. (2019). Effects of a moderate-intensity aerobic exercise programme on the cognitive function and quality of life of community-dwelling elderly people with mild cognitive impairment: A randomised controlled trial. International Journal of Nursing Studies, 93, 97-105.

Song, D., Yu, D. S. F., Li, P. W. C., Lei, Y. (2018). The effectiveness of physical exercise on cognitive and psychological outcomes in individuals with mild cognitive impairment: A systematic review and meta-analysis. International Journal of Nursing Studies, 79, 155-164.

Steinberg, M., Leoutsakos, J. M., Podewils, L. J., Lyketsos, C. G. (2009). Evaluation of a home-based exercise program in the treatment of Alzheimer's disease: the Maximizing Independence in Dementia (MIND) study. International Journal of Geriatric Psychiatry, 24(7), 680-705.

Stephen, R., Hongisto, K., Solomon, A., Lonnroos, E. (2017). Physical Activity and Alzheimer's Disease: A Systematic Review. Journals of Gerontology Series A Biological Sciences and Medical Sciences, 72(6), 733-739.

Sun, J., Kanagawa, K., Sasaki, J., Ooki, S., Xu, H., Wang, L. (2015). Tai chi improves cognitive and physical function in the elderly: a randomized controlled trial. Journal of Physical Therapy Science, 27(5), 1467-1471.

Tao, J., Liu, J., Chen, X., Xia, R., Li, M., Huang, M., Li, S., Park, J., Wilson, G., Lang, C. et al. (2019). Mind-body exercise improves cognitive function and modulates the function and structure of the hippocampus and anterior cingulate cortex in patients with mild cognitive impairment. NeuroImage: Clinical, 23, 101834.

Toots, A., Littbrand, H., Bostrom, G., Hornsten, C., Holmberg, H., Lundin-Olsson, L., Lindelof, N., Nordstrom, P., Gustafson, Y., Rosendahl, E. (2017). Effects of Exercise on Cognitive Function in Older People with Dementia: A Randomized Controlled Trial. Journal of Alzheimer's Disease, 60(1), 323-332.

Um, H. S., Kang, E. B., Leem, Y. H., Cho, I. H., Yang, C. H., Chae, K. R., Hwang, D. Y., Cho, J. Y. (2008). Exercise training acts as a therapeutic strategy for reduction of the pathogenic phenotypes for Alzheimer's disease in an NSE/APPsw-transgenic model. International Journal of Molecular Medicine, 22, 529-539.

Van de Winckel, A., Feys, H., De Weerdt, W., Dom, R. (2004). Cognitive and behavioural effects of music-based exercises in patients with dementia. Clinical Rehabilitation, 18(3), $253-260$.

Varela, S., Ayan, C., Cancela, J. M., Martin, V. (2012). Effects of two different intensities of aerobic exercise on elderly people with mild cognitive impairment: a randomized pilot study. Clinical Rehabilitation, 26(5), 442-450.

Venturelli, M., Scarsini, R., Schena, F. (2011). Six-month walking program changes cognitive and ADL performance in patients with Alzheimer. American Journal of Alzheimer's Disease \& Other Dementias, 26(5), 381-388.

Vreugdenhil, A., Cannell, J., Davies, A., Razay, G. (2012). A community-based exercise programme to improve functional ability in people with Alzheimer's disease: a randomized controlled trial. Scandinavian Journal of Caring Sciences, 26(1), 12-19.

Wang, C., Yu, J. T., Wang, H. F., Tan, C. C., Meng, X. F., Tan, L. (2014). Non-pharmacological interventions for patients with mild cognitive impairment: a meta-analysis of randomized controlled trials of cognition-based and exercise interventions. Journal of Alzheimer's Disease, 42(2), 663-678.

Wei, X. H., Ji, L. L. (2014). Effect of handball training on cognitive ability in elderly with mild cognitive impairment. Neuroscience Letters, 566, 98-101.

Williamson, J. D., Espeland, M., Kritchevsky, S. B., Newman, A. B., King, A. C., Pahor, M., Guralnik, J. M., Pruitt, L. A., Miller, M. E., Investigators, L. S. (2009). Changes in cognitive 
function in a randomized trial of physical activity: results of the lifestyle interventions and independence for elders pilot study. Journals of Gerontology Series A Biological Sciences and Medical Sciences, 64(6), 688-694.

Winblad, B., Amouyel, P., Andrieu, S., Ballard, C., Brayne, C., Brodaty, H., Cedazo-Minguez, A., Dubois, B., Edvardsson, D., Feldman, H. et al. (2016). Defeating Alzheimer's disease and other dementias: a priority for European science and society. Lancet Neurology, 15(5), 455-532.

Yang, S. Y., Shan, C. L., Qing, H., Wang, W., Zhu, Y., Yin, M. M., Machado, S., Yuan, T. F., Wu, T. (2015). The Effects of Aerobic Exercise on Cognitive Function of Alzheimer's Disease Patients. CNS \& Neurological Disorders-Drug Targets, 14(10), 1292-1297.

Yoon, D. H., Kang, D., Kim, H. J., Kim, J. S., Song, H. S., Song, W. (2017). Effect of elastic band-based high-speed power training on cognitive function, physical performance and muscle strength in older women with mild cognitive impairment. Geriatrics \& Gerontology International, 17(5), 765-772. 